\title{
Crack Cocaine
}

National Cancer Institute

\section{Source}

National Cancer Institute. Crack Cocaine. NCI Thesaurus. Code C105553.

An illegal drug composed of the smokable, baseform of cocaine that is produced by dissolving cocaine hydrochloride in an alkali solution, usually sodium bicarbonate and water, and subsequent boiling. Cocaine causes euphoria, loss of appetite, insomnia, and is highly addictive. 